\title{
Electrophoretic, Immunologic and Kinetic Characterization of Erythrocyte Pyruvate Kinase in the Basenji Dog with Pyruvate Kinase Deficiency
}

Koji Nakashima, Shiro Miwa, Kenji Shinohara, Etsuko Oda, Mitsuaki Tajiri, Shigenobu Abe, Junichiro Ono and JoHN A. BLACK*

Third Department of Internal Medicine, Yamaguchi University School of Medicine, Ube, Yamaguchi 755, Japan and Department of Biochemistry, * University of Oregon Medical School, Portland, Oregon 97201, U.S.A.

Nakashma, K., Mrwa, S., Shinohara, K., Oda, E., Tajiri, M., Abe, S., Ono, J. and BLACK, J.A. Electrophoretic, Immunologic and Kinetic Characterization of Erythrocyte Pyruvate Kinase in the Basenji Dog with Pyruvate Kinase Deficiency. Tohoku J. exp. Med., 1975, 117 (2), 179-185—The electrophoretic mobility and the immunologic specificity of erythrocyte pyruvate kinase (PK) of the homozygous Basenji dog with PK deficiency were identical to those of normal $M_{2}$-type PK isozyme seen in the white cell but not to those of the erythrocyte PK isozyme. Kinetic properties and stability were also consistent with the $\mathbf{M}_{2}$-type PK isozyme. Defective PK in the homozygous red cell was due to the absence of the erythrocyte PK isozyme and the compensatory presence of $\mathrm{M}_{2}$-type $\mathrm{PK}$ isozyme, as seen in the severe classical type PK deficiency in man. pyruvate kinase deficiency; isozyme; hemolytic anemia; Basenji dog

Since Valentine et al. (1961) discovered pyruvate kinase (PK, ATP: pyruvate phosphotransferase, EC. 2.7.1.40) deficiency with congenital hemolytic anemia, more than 160 cases of either quantitative PK deficiency or qualitative PK defects (variant enzyme) have been documented in man (Tanaka and Paglia 1971). In mammalian tissues, there are three non-interconvertible $\mathrm{PK}$ isozymes, L-type $\mathrm{PK}$ (PK-L), $\mathrm{M}_{1}$-type PK $\left(\mathrm{PK}-\mathrm{M}_{1}\right)$ and $\mathrm{M}_{2}$-type PK (PK-M $\mathrm{M}_{2}$ ) (Imamura et al. 1972; Ibsen and Trippet 1973), and there is also erythrocyte PK (PK-R) which is not identical electrophoretically but closely related kinetically, immunologically and genetically, and convertible to PK-L (Nakashima 1974).

Erythrocyte defective PKs have been discussed with reference to tissue isozymes, and eight different $\mathrm{PK}$ variants and three cases of quantitative PK deficiency have been reported by us in previous kinetic, immunologic and electrophoretic studies (İmamura et al. 1973; Nakashima et al. 1974; Miwa et al. 1975).

In other mammals, a kindred of the Basenji dog was reported to have a

Received for publication, May 15, 1975. 
deficiency of pyruvate kinase which in turn causes congenital hemolytic anemia (Searcy et al. 1971; Standerfer et al. 1974). Black et al. (1975) reported that the erythrocyte $\mathrm{PK}$ of the normal Basenji dog has similar properties to those of man and thus, the Basenji dog with PK deficiency is suitable as a model for human PK deficiency (Standerfer et al. 1975).

The purpose of the present study is to characterize the defective $\mathrm{PK}$ in the Basenji dog by means of biochemical parameters for human PK variants and tissue isozymes, and to clarify the mechanism by which hemolysis is produced in the Basenji dog, as compared with that in human cases.

\section{Materials and Methods}

ACD treated blood of homozygous and heterozygous Basenji dogs and also Labrador Retriever as a normal control was obtained in Portland, Oregon, U.S.A., and was transported to Japan under refrigeration via air mail. Small quantities of each sample were stored under refrigeration in Portland to check the stability of PK activity during transportation and investigation. The sample arrived in satisfactory condition. All studies were performed within 5 days after the blood was obtained, while samples stored in Portland had no significant loss of PK activities. Blood was centrifuged at $1,300 \times \mathrm{g}$ for $10 \mathrm{~min}$ and the red cells were washed three times with normal saline and the buffy coat was removed after each washing. The washed red cells obtained in this way were found microscopically to have negligible white cell contamination. Hemolysates were prepared by saponin hemolysis and diluted in either water or buffer as required for each study as described previously (Nakashima et al. 1974; Miwa et al. 1975).

PK was assayed as described earlier (Miwa et al. 1975). The assay mixture contained $0.1 \mathrm{M}$ Tris- $\mathrm{HCl} \mathrm{pH} 8.0,0.1 \mathrm{M} \mathrm{KCl}, 10 \mathrm{mM} \mathrm{MgCl}$, $1.2 \mathrm{mM}$ ADP, $0.2 \mathrm{mM} \mathrm{NADH}, 2.0 \mathrm{mM}$ phosphoenolpyruvate (PEP) and $6 \mathrm{U} / \mathrm{ml} \mathrm{LDH}$. Tissue homogenate from a normal Shepherd dog was freshly prepared with a mixer-type homogenizer. Kinetic studies for PEP and for ADP, thin layer polyacrylamide gel electrophoresis and urea stability test were performed by the methods reported previously (Nakashima et al. 1974; Miwa et al. 1975) and the conditions are given in the legends of the figures. For the PK neutralization test by antiserum, the same batch of anti-human erythrocyte PK antiserum previously reported (Nakashima 1974; Miwa et al. 1975) was used. In addition, anti-rat PK-M antiserum which had been provided by Dr. T. Tanaka, Osaka University, Japan, was also used in the same fashion.

\section{Results}

PK activities of homozygous Basenji, heterozygous Basenji and Labrador Retriever were $3.24,1.92$ and 4.38 units/g $\mathrm{Hb}$, respectively.

PK electrophoresis gave the results shown in Fig. 1. Labrador Retriever and Shepherd red cell PK had the same migration, which was slower than the liver PK of the Shepherd. On the other hand, the homozygous red cell PK definitely showed migration with the same mobility as those of normal Shepherd white cell and spleen PK. The heterozygote had both bands which showed the same migration as the normal and the homozygote, respectively. Muscle PK had a mobility between those of the spleen and the normal red cell enzymes. Tissue isozyme pattern is the same as that of the human (Imamura et al. 1973) and the rat (Imamura and Tanaka 1972), although the migration of the dog PK-R was slower than that of the 

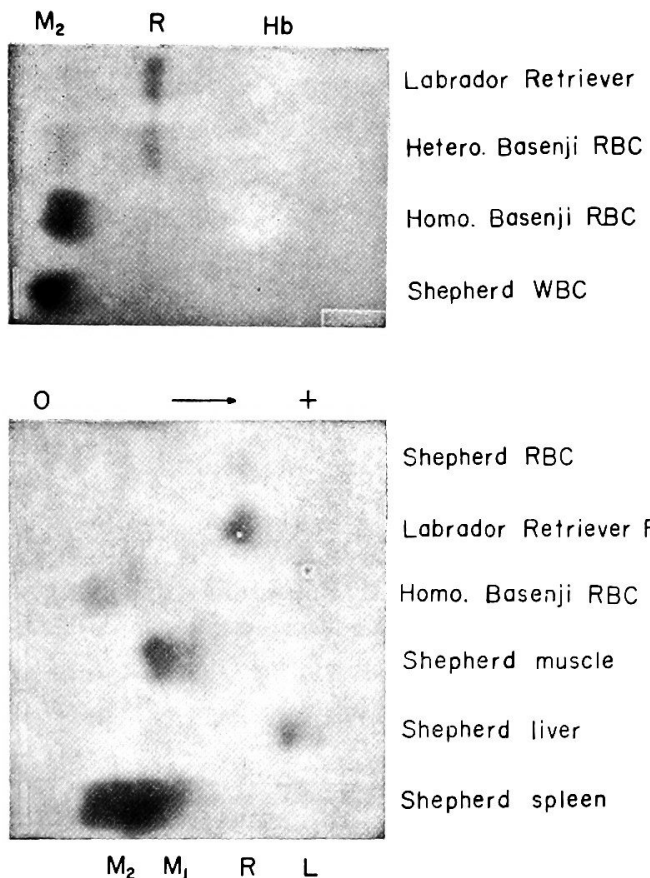

Shepherd RBC

Labrodor Retriever RBC

Homo. Basenji RBC

Shepherd muscle

Shepherd liver

Shepherd spleen

Fig. 1. Thin-layer polyacrylamide gel electrophoresis of pyruvate kinase.

Supporting media: $3.34 \%$ acrylamide gel, $0.1 \mathrm{~cm}$ in thickness.

Buffer: $10 \mathrm{mM}$ Tris-HCl, $\mathrm{pH} 8.2,5.0 \mathrm{mg} \mathrm{MgSO}_{4}, 50 \mathrm{mM}$ Mercaptoethanol, $0.5 \mathrm{mM}$ FDP. Upper plate: voltage $25 \mathrm{~V} / \mathrm{cm}, 5 \mathrm{hr}$.

Lower plate: voltage $20 \mathrm{~V} / \mathrm{cm}, 12 \mathrm{hr}$.

RBC, red cell; $M_{2}, M_{2}$-type PK: R, erythrocyte PK; $M_{1}, M_{1}$-type PK; L, L-type PK.

human. In canine tissue, as had been reported in other mammals (Imamura and Tanaka 1972; Imamura et al. 1973), the liver had PK-L and PK- $\mathrm{M}_{2}$, the muscle had $\mathrm{PK}-\mathrm{M}_{1}$, the spleen and the white cell had PK-M $\mathrm{M}_{2}$ and the red cell had PK-R. These results suggested that the red cell of the homozygote might have $\mathrm{PK}-\mathrm{M}_{2}$ instead of normal PK-R.

The results of PK neutralization tests by antiserum are presented in Fig. 2. The homozygote and the normal had weak neutralization by anti-human erythrocyte PK antiserum and there was no significant difference between them. But using anti-rat PK- $\mathrm{M}_{1}$ antiserum, the hemolysate of the homozygote was markedly neutralized and to the same degree as the extract of normal Shepherd spleen. Neither normal Labrador Retriever red cell nor normal Shepherd red cell was neutralized. These results support the findings of electrophoresis in suggesting that the red cell of the homozygote had the $\mathrm{PK}-\mathrm{M}_{2}$ isozyme.

Kinetic curves for PEP are shown in Fig. 3. The normal and the heterozygote had more sigmoidal curves without FDP reflecting the allosteric nature of the enzyme (Hill's $\mathrm{n}$ value 2.0 and 1.9, Vmax 11.49 and 5.13 units/g $\mathrm{Hb}, \mathrm{Km} 1.7$ and $1.0 \mathrm{mM}$, respectively), but the homozygote had a less sigmoidal curve (Hill's $n$ value 


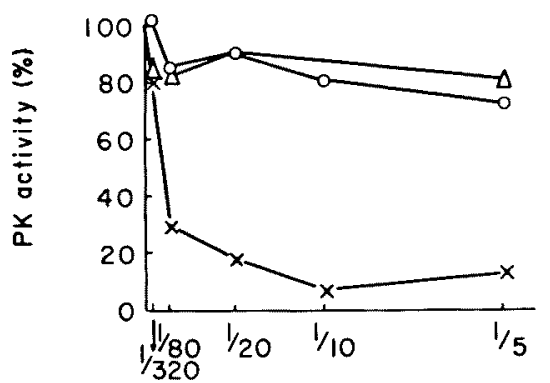

Antiserum

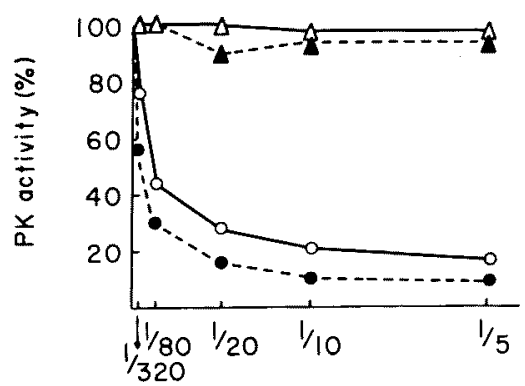

Antiserum

Fig. 2. Pyruvate kinase neutralization by antiserum.

Left: Neutralization by anti-human erythrocyte PK antiserum.

Right: Neutralization by anti-rat PK- $\mathrm{M}_{2}$ antiserum. o, homozygous Basenji RBC; , Labrador Retriever RBC; •, Shepherd spleen; 4, Shepherd RBC; $\times$, normal human RBC.

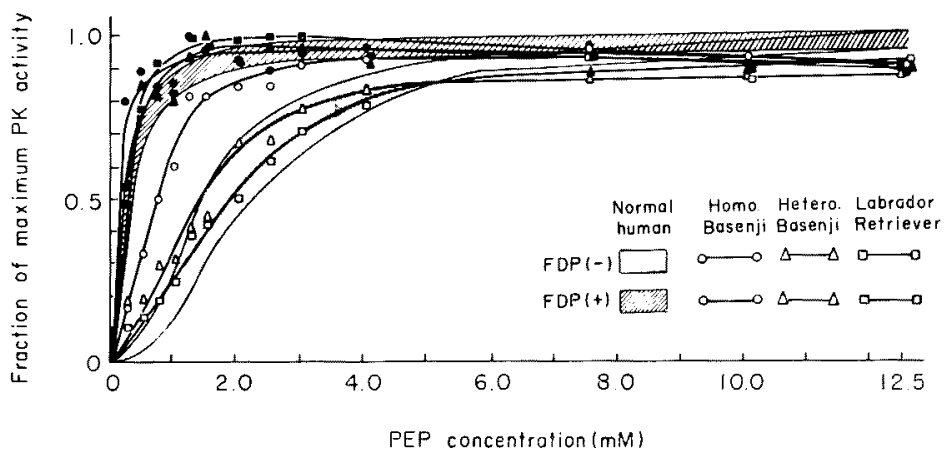

Fig. 3. Pyruvate kinase kinetic curves for PEP, of homozygous and heterozygous Basenji dogs and Labrador Retriever as a normal dog control.

Human normal ranges were obtained from mean \pm S.D. $(n=12)$.

Assay system: $2.0 \mathrm{mM}$ ADP, $0.15 \mathrm{mM} \mathrm{NADH}, 8.0 \mathrm{mM} \mathrm{MgSO}_{4}, 6.0 \mathrm{mM}$ EDTA, 75 $\mathrm{mM} \mathrm{KCl}, 6.0 \mathrm{U} / \mathrm{ml} \mathrm{LDH}$ and varied concentrations of PEP in $0.2 \mathrm{M}$ Tris-HCl buffer, $\mathrm{pH} 8.0$, at $37^{\circ} \mathrm{C}$. FDP $(+), 0.5 \mathrm{mM}$ FDP; FDP $(-)$, absence of FDP.

1.7, Vmax 7.14 units/g $\mathrm{Hb}, \mathrm{Km} 0.3 \mathrm{mM}$ ) despite the alkaline $\mathrm{pH}$ (Koster et al. 1971; Nakashima et al. 1974). Fructose 1,6-diphosphate (FDP) lowered the Kms and there was no difference among the samples. The findings of the kinetic curves for ADP and the ATP inhibition tests were almost identical to those reported by Standerfer et al. (1975).

Urea stability tests showed that the homozygous $\mathrm{PK}$ was inactivated to $84 \%$ of initial activity after $40 \mathrm{~min}$, the heterozygous $\mathrm{PK}$ to $50 \%$ and the normal to $61 \%$, and also that the homozygote was more unstable than the normal as seen in the stability test of the previous report (Standerfer et al. 1974). 


\section{Discussion}

The differences of the enzyme properties between the homozygote and the normal have already been reported by Standerfer et al. (1975) and their findings, which we confirmed, such as kinetics for PEP and ADP, less inhibition by ATP and instability, are very similar characteristics to $\mathrm{PK}-\mathrm{M}_{2}$ observed in other mammals (Koler et al. 1968; Imamura et al. 1972). Greater solubility of PK of the homozygote in ammonium sulfate solutions than the normal erythrocyte PK (Standerfer er al. 1975) was also observed in human PK-M $\mathrm{M}_{2}$ (Koler et al. 1968) and in rat $\mathrm{PK}-\mathrm{M}_{2}$ (Imamura et al. 1972).

Electrophoretic mobility of the homozygous PK was identical to that of normal $\mathrm{PK}-\mathrm{M}_{2}$.

The findings of $\mathrm{PK}$ neutralization suggested to us that our anti-human erythrocyte PK antibody had less affinity for the dog erythrocyte PK because there exists a high species specificity of the erythrocyte PKs in both mammals. But $\mathrm{PK}-\mathrm{M}_{2}$ is considered to be a prototype $\mathrm{PK}$ isozyme in mammals and to be more poorly differentiated through the evolutionary process than the erythrocyte PK (Imamura et al. 1972). Therefore, anti-rat $\mathrm{PK}-\mathrm{M}_{2}$ antiserum cross-react well to the dog $\mathrm{PK}-\mathrm{M}_{2}$ in spite of the difference of species, but did not cross-react to the dog erythrocyte PK. Another possibility is that different batches of antiserum produce different affinities to antigenic analogs.

From these findings it is considered that the red cell PK of the homozygote consists of normal canine PK- $\mathrm{M}_{2}$ instead of either normal PK-R or mutant PK-R although there may exist inactive mutant erythrocyte PK.

We reported three cases of human PK deficiency with normal PK- $\mathrm{M}_{2}$ and nondetectable PK-R, as "classical type PK deficiency" (Imamura et al. 1973; Niwa and Nishina 1974; Nakashima et al. 1974; Miwa et al. 1975). Biochemical characteristics of these human cases are similar to those of the homozygous Basenji except for relatively high activity in the Basenji (Searcy et al. 1971; Standerfer et al. 1974). Standerfer et al. $(1974 ; 1975)$ reportedthat PK activity in the homozygous red cell was high and postulated that the impaired stability is the cause of rapid loss of activity during cell senescence which is followed by hemolysis. This must be true. However, our assay system showed subnormal activity. As seen in the kinetic studies, low $\mathrm{Km}$ for PEP and high $\mathrm{Km}$ for ADP may produce different activities in different assay conditions. Indeed, in our staining of electrophoresis, the homozygote produced a stronger band than expected from the activity assayed by us, and further dilution was needed to make the zymogram presented in Fig. 1. This observation also suggested that actual red cell PK activity in vivo where the substrate concentrations are low may be different from the in vitro assay value, and that $\mathrm{PK}-\mathrm{M}_{2}$ in the red cell, although it may be a compensatory presence for the deficient erythrocyte PK isozyme, is not physiological in the circulating red cell and further may produce defective glycolysis. The homozygous Basenji was reported to have impaired glycolytic activity despite the increased young cell 
populations with high PK activity (Searcy et al. 1971).

This observation indicates that defective glycolysis exists, despite the compensatory presence of $\mathrm{PK}-\mathrm{M}_{2}$, and that the existence of the physiological isozyme is essential for normal metabolism in each tissue, especially in highly differentiated tissue, such as the red cell.

\section{Acknowledgments}

This work was supported in part by grants from the Ministry of Education (Nos. 837010 and 857049) and Research Grant for Specific Diseases from the Ministry of Health and Welfare, Japan. The finanical support of the dogs from the Medical Research Foundation of Oregon and RR 00389 from the U.S. Public Health Service is also acknowledged. We wish to thank Dr. T. Tanaka, Osaka University, Japan, who kindly provided us with anti-rat PK-M $\mathrm{M}_{2}$ antiserum.

\section{References}

1) Black, J.A., Chern, C.J. \& Rittenberg, M.B. (1975) Canine erythrocyte pyruvate kinase. I. Properties of the normal enzyme. Biochem. Genet., 13, 331-339.

2) Ibsen, K.H. \& Trippet, P. (1973) A comparison of kinetic parameters obtained with three major non-interconvertible isozymes of rat pyruvate kinase. Arch. Biochem. Biophys., 156, 730-744.

3) Imamura, K. \& Tanaka, T. (1972) Multimolecular forms of pyruvate kinase from rat and other mammalian tissues. I. Electrophoretic studies. J. Biochem., 71, 10431051.

4) Imamura, K., Taniuchi, K. \& Tanaka, T. (1972) Multimolecular forms of pyruvate Kinase. II. Purification of $\mathrm{M}_{2}$-type pyruvate kinase from Yoshida ascites hepatoma 130 cells and comparative studies on the enzymological and immunological properties of the three types of pyruvate kinase, $\mathrm{L}, \mathrm{M}_{1}$ and $\mathrm{M}_{2}$. J. Biochem., 72, 1001-1015.

5) Imamura, K., Tanaka, T., Nishina, T., Nakashima, K. \& Miwa, S. (1973) Studies on pyrvuate kinase (PK) deficiency. II. Electrophoretic, kinetic and immunological studies on pyruvate kinase of erythrocytes and other tissues. $J$. Biochem., 74, 11651175 .

6) Koler, R.D., Bigley, R.H. \& Stenzel, P. (1968) Biochemical properties of human erythrocyte and leukocyte pyruvate kinase. In: Hereditary Disorders of Erythracyte Metabolism, edited by E. Beutler, Grune \& Straton, New York and London, pp. 249-264.

7) Koster, J.F., Staal, G.E. \& van Milligen-Boersma, L. (1971) The effect of urea and temperature on red blood cell pyruvate kinase. Biochim. Biophys. Acta, 235, $362-365$.

8) Miwa, S. \& Nishina, T. (1974) Studies on pyruvate kinase (PK) deficiency. I. Clinical, hematological and erythrocyte enzyme studies. Acta haematol. Jap., 37, 1-16.

9) Miwa, S., Nakashima, K., Ariyoshi, K., Shinohara, K., Oda, E. \& Tanaka, T. (1975) Four new pyruvate kinase (PK) variants and a classical PK deficiency. Brit. J. Haematol., 29, 157-169.

10) Nakashima, K., Miwa, S., Oda, S., Tanaka, T., Imamura, K. \& Nishina, T. (1974) Electrophoretic and kinetic studies of mutant erythrocyte pyruvate kinases. Blood, 43, 537-548.

11) Nakashima, K. (1974) Further evidence of molecular alteration and aberration of erythrocyte pyruvate kinase. Clin. chim. Acta, 55, 245-254.

12) Searcy, C.P., Miller, D.R. \& Tasker, J.B. (1971) Congenital hemolytic anemia in the Basenji dog due to erythrocyte pyruvate kinase deficiency. Canad. J. comp. Med., $35,67-70$. 
13) Standerfer, R.J., Templeton, J.W. \& Black, J.A. (1974) Anomalous pyruvate kinase deficiency in the Basenji dog. Amer. J. vet. Res., 35, 1541-1543.

14) Standerfer, R.J., Rittenberg, M.B., Chern, C.J., Templeton, J.W. \& Black, J.A. (1975) Canine erythrocyte pyruvate kinase. II. Properties of the abnormal enzyme associated with hemolytic anemia in the Basenji dog. Biochem. Genet., 13, 341-351.

15) Tanaka, K.R. \& Paglia, D.E. (1971) Pyruvate kinase deficiency. Sem. Hematol., 8, 367-396.

16) Valentine, W.N., Tanaka, K.R. \& Miwa, S. (1961) A specific erythrocyte glycolytic enzyme defect (pyruvate kinase) in three subjects with congenital non-spherocytic hemolytic anemia. Trans. Ass. Amer. Physicians, 74, 100-110. 